\title{
Response of People with Type 1 Diabetes for Follow Up
}

\author{
Sarfraz Ahmad Khan ${ }^{1}$, Faiza Kamal ${ }^{2}$, Rozina Arshad ${ }^{2}$, Bilal Bin Younis ${ }^{2}$, Rashid Ahmed ${ }^{2}$ \\ DHQ Teaching Hospital Sahiwal ${ }^{1}$, Department of Medicine, Shalamar Medical\& Dental College, Lahore ${ }^{2}$
}

\begin{abstract}
Diabetes is becoming a global epidemic. Type1 diabetes (T1DM) accounts for 3-5\% of all the diabetics. As T1DM is diagnosed in childhood and adolescence, it is associated with more complications because of longer life span of individuals with this condition. The main objective of the study was to find out attitudes of people with type 1 diabetes especially with regards to their follow up. A cross-sectional study was planned and a total of 97 people with type 1 diabetes were included for a period of one year. To analyze the data SPSS 20.0 version was used. Results showed that out of 97 people, 48 (49.5\%) were male and $49(50.5 \%)$ were female. The mean age of total type 1 diabetics were $17.03 \pm 6.54$ years. Mean glycated hemoglobin (HbA1c) was $10.59 \pm 3.09$. The results revealed that $45 \%$ of people showed positive attitude and $55 \%$ showed negative behavior towards follow-up. It was concluded that overall follow up of people with type 1 diabetes was poor. It was observed that they wanted a complete cure and this contribute to missed follow up.
\end{abstract}

\section{INTRODUCTION}

Diabetes is a long standing health problem. According to $\mathrm{WHO}$, diabetes comes at 4 th position in non-communicable diseases like heart attack, stroke, cancer, and chronic respiratory disease. It is categorized by hyperglycemia that is increased levels of glucose in blood due to inadequate amount of insulin and insulin resistance ${ }^{1}$. Diabetes is a serious health concern all over the world including Pakistan. According to International Diabetes Federation (IDF) 387 million individuals have diabetes worldwide ${ }^{2}$. This is expected to be 592 million in 2035 with the increase of $53 \%$ all over the world and $85 \%$ increase in Middle East and North Africa (MENA) region. Type 1 diabetes is caused by inability of the body to produce the insulin it requires and body's own defense system attacks insulin producing beta cells in the pancreas. It generally affects children and young adults. Fortunately, T1DM only accounts for $3-5 \%$ of all the diabetics. For their survival, people with T1DM are dependent on peripheral sources of insulin ${ }^{3}$. Diabetes is not only a disease it's a developmental concern. If left untreated it leads to short term and long term complications. People with T1DM require a wide range of health care professionals to achieve good glycemic control and to minimize the cost and related end stage complications ${ }^{4}$.

\section{MATERIAL AND METHODS}

A cross-sectional study was planned to assess the attitudes of people with T1DM towards follow up. The study was conducted from December 2016 December 2017. Only People with type 1 diabetes were included. People with T2DM, GDM and pregnant ladies with T1DM were excluded. A total of 98 people with T1DM were contacted, it was noted that one patient who was lost in follow up died during this period. Data of 97 patients was recorded. The data was analyzed using SPSS 20.0 version (Statistical Package for the Social Sciences).

\section{RESULTS}

Table 1 shows that out of 97 people with T1DM, there was almost equal distribution amongst the gender. The mean age of total type 1 diabetics were $16.03 \pm 6.54$ years. Mean HbA1c was $11.59 \pm 3.09$. About $61 \%$ of the people with T1DM belong to low socioeconomic status and fall in general group. The data for number of pricks revealed that $49 \%$ people pricked twice a day and $37.8 \%$ pricked thrice whereas more than 4 pricked were noticed in only $6.79 \%$. 
Table 1: Basic clinical characteristic

\begin{tabular}{|l|l|}
\hline Parameters & \\
\hline Age (years) & $16.03 \pm 6.54$ \\
\hline Gender & \\
\hline Male $\mathrm{n}(\%)$ & $48(49.5 \%)$ \\
\hline Female $\mathrm{n}(\%)$ & $49(50.5 \%)$ \\
\hline HbA1c (\%) & $11.59 \pm 3.09$ \\
\hline Socioeconomic class & \\
\hline General $\mathrm{n}(\%)$ & $59(60.85)$ \\
\hline Private $\mathrm{n}(\%)$ & $38(39.2 \%)$ \\
\hline Frequencies of pricks & \\
\hline $2 \mathrm{n}(\%)$ & $51(49.47 \%)$ \\
\hline $3 \mathrm{n}(\%)$ & $39(37.8 \%)$ \\
\hline More than $4 \mathrm{n}(\%)$ & $7(6.79 \%)$ \\
\hline
\end{tabular}

Figure 1 shows the response of patients with T1DM; they were asked to visit the center for an educational group session. The people who showed positive feedback were $45 \%$ and $55 \%$ showed little or no interest.

FIG: 1 Response of Type 1 Diabetic People towards Follow up

\section{Response Towards Follow up}

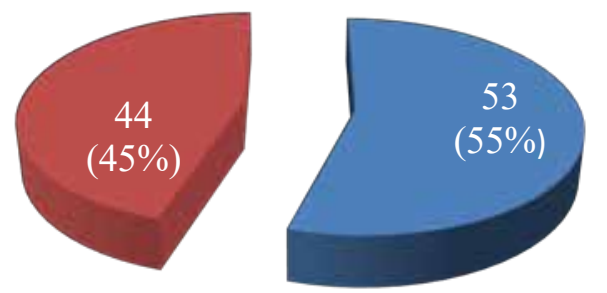

Positive attitude

\section{DISCUSSION}

According to IDF survey in 8 African countries, one of the major principle hazards in the health system is the dependence of people with T1DM on traditional medicine in treating diseases rather than use of allopathic medicine. Traditional healers and health quacks do not talk about the disease with the people having T1DM. This is because they are themselves not aware of the pathogenesis and complications of the disease. They often mislead the people with T1DM regarding treatment of the disease $^{6}$. In Pakistan, government is offering planned educational programs for homeopathic and "Tibb" (herbal medicine) and offering them license to practice in the country. However, the regulatory bodies are not effectively monitoring their activities nor have they defined their sphere of responsibilities. One of the reasons to skip follow up in people with T1DM is that they want total cure and they hesitate or get frustrated with the use of insulin and rush towards them. According to a study published in Pakistan at Gomal Journal of Medical Sciences, which was conducted at Nishtar Hospital, Multan. It was also shown that one of the reasons of non-compliance in the diabetic patient is not keeping up with their follow up visits ${ }^{7}$. In our study it was seen that $45 \%$ of type 1 diabetic people showed positive feedback and 55\% showed little or no interest towards follow up. A study published in Journal of Community Medicine showed the regularity of follow up of diabetic patients in the clinic. The results showed that only $7.9 \%$ of the participants never missed any appointment in the last year, although near to half of them missed appointments $49.9 \%$ once or twice and $41 \%$ more than twice. Half of the respondents $(50 \%)$ didn't showed up on the day of interview, and out of half of them $42.9 \%$ stated inaccessibility of transport, $15.5 \%$ said they had forgotten whereas $28.7 \%$ ignored as they are taking medicine from other sources $^{8}$. These different type of responses draw attention towards the establishment of a systemized health care system, by which health care facilities are provided to people with T1DM through continuous contact and awareness about regular follow ups. In this way the long term complications of diabetes can be prevented ${ }^{9}$.It is a well proven fact that tighter control of blood glucose level can go a long way in preventing the complications in diabetes ${ }^{10}$. In our study the pregnant ladies with T1DM were not included however the follow up in female type 1 diabetics there is even more importance especially in childbearing age as it is concerned with two lives and a planned pregnancy is always advisable for a better outcome of mother and child. In uncontrolled pregnant mothers the large sized babies are at a higher risk of developing prenatal complications and future diabetes ${ }^{11}$. 


\section{CONCLUSION}

It is concluded from our study that only a small number of people with T1DM showed positive response towards follow up. The HbA1c levels were significantly poor. It is therefore suggested that in our part of the world, we need to put in more effort regarding the awareness of diabetes as a whole and especially T1DM as these younger individual are future hope of our country and a more prone to be misguided by the people who claim to cure the disease. We also recommend that the government implement rationale legislations regarding the advertisement and activities of all registered medical practitioners.

\section{REFERENCES}

1. Colagiuri R, Brown J, Dain K. Global diabetes plan 2011-2021. International Diabetes Federation. Brussels; 2011.

2. Federation ID. IDF Diabetes Atlas update poster. International Diabetes Federation. 2014.

3. Loghmani E. Diabetes Mellitis: Type 1 And Type 2, Chapter 14, Stang J, Story M (Eds) Guidelines for Adolescent Nutrition Services; 2005.

4. Gillespie KM. Type 1 diabetes: pathogenesis and prevention. Cmaj. 2006 Jul 18;175(2):165-70.

5. Nathan DM, Kuenen J, Borg R, Zheng H, Schoenfeld D, Heine RJ. Translating the A1C assay into estimated average glucose values. Diabetes care. 2008 Aug 1;31(8):1473-8.
6. Mbanya JC, Motala AA, Sobngwi E, Assah FK, Enoru ST. Diabetes in sub-saharanafrica. The lancet. 2010 Jun 26;375(9733):2254-66.

7. Imtiaz S, Ullah H, Rasool MF, Hashmat F, Saleem M, Khan N. Assessment of compliance of diabetic patients at Nishtar Hospital Multan, Pakistan. Gomal J Med Sci. 2014 Jun 30;12(2):84-

8. Khan AR, Lateef ZN, Al Aithan MA, Bu-Khamseen MA, Al Ibrahim I, Khan SA. Factors contributing to non-compliance among diabetics attending primary health centers in the Al Hasa district of Saudi Arabia. Journal of Family and Community Medicine. 2012 Jan;19(1):26-32.

9. Shrivastava SR, Shrivastava PS, Ramasamy J. Role of self-care in management of diabetes mellitus. Journal of Diabetes \& Metabolic Disorders. 2013 Dec;12(1):14.

10. DCCT Research Group. Factors in development of diabetic neuropathy: baseline analysis of neuropathy in feasibility phase of Diabetes Control and Complications Trial (DCCT). Diabetes. 1988 Apr 1;37(4):476-81.

11.Evers IM, de Valk HW, Visser GH. Risk of complications of pregnancy in women with type 1 diabetes: nationwide prospective study in the Netherlands. Bmj. 2004 Apr 15;328(7445):915.

\section{Corresponding Author:}

Dr Sarfraz Ahmad Khan

Dr.sarfrazahmadkhan@gmail.com

DHQ Teaching Hospital Sahiwal

Email:dr.sarfrazahmadkhan@gmail.com 